Fanum

Sociológico

\section{Forum Sociológico}

Série II

$27 \mid 2015$

Mobilidade científica \& imigração qualificada

\title{
Mobilidade científica e imigração qualificada : situando o debate
}

Beatriz Padilla e Thais França

\section{(2) OpenEdition}

\section{Journals}

\section{Edição electrónica}

URL: https://journals.openedition.org/sociologico/1323

DOI: 10.4000/sociologico.1323

ISSN: 2182-7427

\section{Editora}

CICS.NOVA - Centro Interdisciplinar de Ciências Sociais da Universidade Nova de Lisboa

\section{Edição impressa}

Data de publição: 21 dezembro 2015

Paginação: 7-10

ISSN: 0872-8380

\section{Refêrencia eletrónica}

Beatriz Padilla e Thais França, «Mobilidade científıca e imigração qualificada : situando o debate»,

Forum Sociológico [Online], 27 | 2015, posto online no dia 28 maio 2016, consultado o 31 março 2022.

URL: http://journals.openedition.org/sociologico/1323 ; DOI: https://doi.org/10.4000/sociologico.1323 


\title{
MOBILIDADE CIENTÍFICA E IMIGRAÇÃO QUALIFICADA: SITUANDO O DEBATE
}

\author{
Beatriz Padilla \\ Instituto Universitário de Lisboa (ISCTE-IUL), Centro de Investigação e Estudos de Sociologia (CIES-IUL) \& Universida- \\ de Nova de Lisboa, Centro Interdisciplinar de Ciências Sociais (CICS.NOVA) \\ Thais França \\ Universidade do Minho, Centro Interdisciplinar de Ciências Sociais, CICS.NOVA (Polo UMinho)
}

\begin{abstract}
Resumo
O propósito deste breve artigo é introduzir o debate sobre a mobilidade científica e a imigração qualificada, recorrendo a uma revisão bibliográfica minuciosa que problematiza de forma crítica a complexidade do fenómeno, considerando seu aspecto multifacetado e as distintas variáveis envolvidas em sua configuração. Mais ainda, chama a atenção para temas que via de regra são invisibilizadas nessas discussões: desigualdades raciais, de género e assimetrias geopolíticas.
\end{abstract}

Palavras-chave: mobilidade científica, imigração qualificada, desigualdades sociais

\begin{abstract}
The aim of this brief article is to introduce the debate on scientific mobility and skilled migration through presenting a detailed literature review that critically problematizes the complexity of the phenomena, considers its multifaceted aspect and the different variables involved. Furthermore, it highlights topics rarely discussed: racial and gender inequalities and geopolitical asymmetries.
\end{abstract}

Keywords: scientific mobility, skilled migration, social inequality

De entre as distintas configurações que a imigração qualificada vem assumindo nas últimas décadas, os programas de mobilidade e cooperação científica transnacional destacam-se como uma modalidade de grande relevância para o desenvolvimento económico, tecnológico e social global.

A percepção de que o conhecimento constitui um factor fundamental para o crescimento económico de um país ou bloco económico contribuiu para a intensificação da deslocação de académicos/as, investigadores/as e cientistas por diferentes instituições internacionais na busca de aprendizagem de novas técnicas de investigação e teorias analíticas, partilha dos custos de experiências e projectos de investigação e transferências de tecnologias, alargando e multiplicando os frutos da ciência e do conhecimento científico.

Contudo, é importante ressaltar que a mobilidade de cientistas e académicos/as por diferentes instituições ao redor do mundo não é um fenómeno novo. São inúmeros os relatos deste tipo de deslocação geográfica de estudiosos/as e professores/ /as no antigo Império Chinês, nos países árabes e na Europa medieval, assim como também entre a Europa e a América Latina, no momento em que a circulação de ideias através da formação universitária e outros intercâmbios significou um impulso no pensamento político, social e científico latinoamericano. A diferença que se apresenta neste momento histórico, como em tantos outros fenómenos, é o grau, a proporção, a frequência, a intensidade e a direcção em que essas mobilidades acontecem.

Os processos de globalização hegemónicos são um traço marcante da contemporaneidade. Por sua vez, as transformações que a eles se encontram associadas, reconhecidas nas análises de quase todos os fenómenos sociais que se verificam no momento presente, atingem igualmente os esque- 
mas de mobilidade científica. A redução dos custos de transporte, o aprimoramento das tecnologias de comunicação, a formação de blocos económicos e a própria concorrência entre eles, somados à típica curiosidade intelectual, contribuíram, de forma decisiva, para a intensificação das deslocações científicas e académicas.

Esses novos contornos da mobilidade académica e científica levaram ao aparecimento de diferentes leituras que procuraram ultrapassar algumas das antigas concepções do fenómeno que não logravam explicar a sua complexidade e que, por regra, não estavam isentas de determinados interesses ideológicos e políticos. Durante os anos 50 e 60 as discussões sobre a mobilidade de cientistas, académicos/as, professores/as e investigadores/as giravam em torno, principalmente, do paradigma da "fuga de cérebros". Isto é, o entendimento de que os países do centro teriam mais condições de atrair para seu o mercado laboral - em virtude de ofertas económicas, possibilidades de desenvolvimento de carreira e infraestruturas superiores - os/ /as melhores/as e mais brilhantes trabalhadores/as dos países periféricos. A questão que se colocava nesta dinâmica, remete para as consequências negativas para os países emissores da perda quase irreparável de recursos qualificados e de mão-de-obra de ponta, tendo em conta o investimento que realizaram (em muitos casos produto de educação universitária gratuita), revertendo os "spillovers" para os países mais ricos.

Com o avanço das discussões e análises sobre o fenómeno, optou-se por substituir o conceito "fuga de cérebros" pelo de "ganho" e "circulação de cérebros". Essa linha de interpretação, baseando-se em perspectivas ideológicas e teóricas de cunho mais neoliberal, analisa a mobilidade científica considerando o contexto tanto do país de origem como o do de destino. Mais ainda, considera que um/a investigador/a, cientista ou académico/a, ao sair do seu país de origem para outro, continuaria a manter os seus laços locais de cooperação e de trabalho formais ou informais, através da participação em projectos de cooperação, publicações em revistas locais, orientação de doutorandos/as no outro país, inclusão do país de origem em redes internacionais, de tal forma, que o país emissor beneficiaria tanto quanto o país receptor dessa deslocação. Ao sobrevalorizar os benefícios e as vantagens resultantes desses "intercâmbios", tal leitura tende, no entanto, a minimizar e despolitizar o debate sobre as consequências negativas que a saída de cientistas e intelectuais pode gerar para os países de origem.

Por isso, embora essa nova compreensão seja bastante interessante e dê visibilidade a outros aspectos das dinâmicas de mobilidade que se encontravam encobertos, é preciso cautela e criticidade ao analisá-la. Com efeito, a substituição de um conceito por outro não faz com que antigas formas de desigualdade e assimetria deixem automaticamente de existir. Por exemplo, ainda hoje, as mobilidades académicas e científicas sucedem, principalmente, no sentido periferia-centro. Os países centrais continuam a ser os grandes controladores das tecnologias de ponta e das produções científicas e académicas. Uma vez que os países periféricos não têm condições de competir de igual para igual, estes não só pagam um alto preço para ter acesso a esses avanços como não veem as suas contribuições teóricas serem reconhecidas, de forma paritária, nos meios científicos e académicos. Reconhecer a persistência dessas desigualdades obriga a questionar até que ponto os países da periferia realmente beneficiariam com a deslocação dos/das seus/suas investigadores/as, académicos/as e cientistas para os países do centro.

Um outro aspecto relevante a ser considerado nas análises da mobilidade científica diz respeito aos discursos presentes na construção do fenómeno. $\mathrm{Na}$ literatura hegemónica identifica-se um discurso de enaltecimento da mobilidade científica e dos seus benefícios. Costuma-se ressaltar o aumento da produtividade, crescimento das publicações conjuntas, transferência de técnicas e tecnologias, partilha de modelos de políticas públicas e programas sociais, aprofundamento e conhecimento de diferentes escolas de pensamento e teorias, redução nos custos da pesquisa, promoção da diversidade cultural e aprendizagem de outras línguas e culturas. De fato, essas são inegáveis contribuições para o avanço e melhoria da ciência e das prácticas de produção de conhecimento. Porém, a mobilidade científica constitui-se como um fenómeno multifacetado atravessado por diferentes escalas de estruturação, que se verificam a nível macro - aspectos políticos, económicos, sociais -, meso - políticas institucionais, acordos de cooperação, interesses locais -, e micro - género, raça, etnia, religião, orientação sexual, arranjos familiares e idade. Portanto, as análises acerca da mobilidade científica devem considerar essa complexidade, procurando compreender de que maneira essas diferentes escalas e perspectivas se articulam e contribuem para moldar de forma diferenciada e específica a experiência de investigadores/as, académicos/as e cientistas de acordo com a sua localização no interior dessa matriz. Assim, hierarquias e assimetrias geopolíticas, relações pós-coloniais, ligações e conexões históricas, interesses institucionais, o racismo, o sexismo ou a discriminação étnica e religiosa devem ser considerados nos estudos que se debruçam sobre a mobilidade académica, almejando dar visibilidade a questões que, por regra, são minimizadas pelo discurso hegemónico.

Reflexões acerca de como as diferenças de género, de raça e as questões pós-coloniais se articulam com a mobilidade científica permitem ilustrar a complexidade da matriz dos vectores sociais que a 
atravessam. Contudo, a maioria dos estudos sobre o tema não consideram as referidas questões.

Os estudos feministas reivindicam que todas as análises dos fenómenos sociais devem ter em atenção as hierarquias e assimetrias de poder entre homens e mulheres. Portanto, os estudos sobre mobilidade académica e científica devem considerar a forma como a estrutura patriarcal e androcêntrica da nossa sociedade afecta a concepção dos programas de mobilidade académica e científica, contribuindo para o aumento da exclusão das mulheres desses programas e, consequentemente, dificultando o desenvolvimento das suas carreiras.

A compressão da mobilidade científica como uma etapa da carreira profissional de investigadores/ /as, cientistas e académicos/as força uma reflexão sobre como os mecanismos de segregação sexual do mercado laboral segregação vertical e horizontal do trabalho, tecto e paredes de vidro, hiato salarial, exclusão de redes informais e formais de socialização e de programas de tutoria, desvalorização do conhecimento produzido pelas mulheres, assédio moral e sexual -, e construção desigual dos papéis de género, que atribui às mulheres as responsabilidades familiares e domésticas, moldam o planeamento, a constituição e o andamento desses programas. Soma-se a isso a construção da carreira académica e científica a partir de um modelo primordialmente masculino, pautado pela linearidade, continuidade e dedicação intensa ao trabalho e pela remissão da vida familiar para segundo plano.

Uma reflexão semelhante pode ser feita quando se analisa como as desigualdades étnicas e raciais atravessam a experiência de mobilidade científica de investigadores/as, académicos/as e cientistas. As diferenças raciais e étnicas são uma construção social e ideológica que hierarquiza determinados grupos de pessoas com base em diferenças biológicas e culturais. Ao analisar a relação metrópole-colónia, a partir de uma perspectiva descolonial, Quijano (2009) identifica as prácticas e discursos que legitimaram e reforçaram o imaginário social dos povos das colónias como bárbaros, incivilizados e tradicionais, enquanto a metrópole era construída como locus de civilização e modernidade. Assim, a metrópole tornou-se não apenas o centro de poder económico, mas, igualmente, de produção de conhecimento e saber. Nesta relação, os sujeitos das colónias foram construídos como inferiores, subalternos e exóticos, em oposição aos racionais, superiores e modernos sujeitos das metrópoles.

Já o conceito de orientalismo de Said (1979), sobre a construção do Oriente pelo Ocidente como "o Outro", desconhecido, exótico e igualmente inferior como as colónias, oferece elementos para a compreensão de como se legitimou o homem branco e ocidental como modelo ideal de cientista, excluindo ou inferiorizando os indivíduos oriundos/ /as das ex-colónias e do Oriente.

Se numa perspectiva micro, os/as investigadores/as, académicos/as e cientistas são os/as protagonistas dos programas de mobilidade científica, numa perspectiva meso e macro as instituições de ensino e investigação e os Estados Nação detêm o papel principal. Como foi dito anteriormente, um dos principais benefícios resultantes da mobilidade consiste na transferência de tecnologia e na circulação de conhecimento. Contudo, trata-se também de uma dinâmica complexa que abarca diferentes escalas sociais, económicas e políticas. Para que a circulação de conhecimento, transferência de tecnologias e a consolidação de redes de investigação realmente aconteça é necessário que os países envolvidos trabalhem numa perspectiva de cooperação horizontal, reconhecendo não apenas as múltiplas realidades académicas e científicas, mas também a realidade social, política e económica a fim de encontrar estratégias eficazes que permitam alcançar os objectivos propostos, responder a necessidades e interesses dos vários contextos nacionais e gerar agendas partilhadas. Neste sentido, os estudos acerca da mobilidade científica devem analisar também de forma aprofundada a realidade local, os interesses, o papel e as estratégias dos diferentes actores institucionais envolvidos nos programas.

Ainda considerando uma perspectiva de macro análise e a forma como alguns discursos moldam a compreensão da mobilidade académica e científica é preciso questionar até que ponto essa mobilidade se constitui verdadeiramente como uma estratégia de desenvolvimento de carreira e não como o resultado do avanço da precarização laboral deste sector. Costuma-se apresentar a mobilidade científica como imprescindível para o desenvolvimento de carreira uma vez que possibilita o conhecimento de novas técnicas de investigação e teorias analíticas, promove a criatividade, o contacto com novas culturas e ganhos pessoais - como a aprendizagem de novas línguas, a abertura a diversidade e o exercício da reflexibilidade. Desta forma, legitima-se um discurso que apresenta a mobilidade científica como uma experiência profissional fundamental que oferece mais benefícios individuais do que propriamente institucionais. Contudo, é preciso levar em consideração o contexto em que esse discurso se constrói e analisar até que ponto os benefícios ou prejuízos resultantes da participação em programas de mobilidade científica perpassam o meramente pessoal. 0 avanço das políticas neoliberais tem forçado a uma redução nos cortes orçamentais em todas as áreas, incluindo educação, ciência e tecnologia - embora, as ciências aplicadas, as tecnologias e alguns campos da saúde sejam, em geral, menos afectados obrigando as instituições a procurar alternativas de financiamento e gestão económica. A diminuição da 
oferta dos postos de trabalho a tempo indeterminado, com contratos que assegurem direitos do trabalho aos/as investigadores/as, académicos/as e cientistas tem-se intensificado. Assim, bolsas de estudo e de investigação e contratos temporários, têm-se vindo a tornar as modalidades mais comuns de inserção no sector académico e científico. A instabilidade da renovação dos contratos e a escassez de ofertas de postos de trabalho tem forçado, sob a justificação das vantagens da internacionalização da carreira científica, aqueles/as que aspiram uma carreira académica científica a deslocarem-se internacionalmente em busca de oportunidades. Porém, mais do que uma deslocação voluntária, fruto de um plano de carreira, o trânsito científico e académico tem-se tornado em diversos casos uma obrigatoriedade, em virtude da falta de oportunidades locais imediatas. Neste sentido, apesar de a mobilidade científica poder ser concebida como um grande momento profissional, as dinâmicas de precarização que a atravessam não podem ser minimizadas ou desconsideradas.

Por fim, a última questão a ser levantada, embora não seja menos importante, é a própria escolha do termo utilizado para nomear o fenómeno da deslocação geográfica internacional de investigadores/ /as, cientistas e académicos/as por entre distintas instituições. As discussões hegemónicas sobre mobilidade científica apoiam-se no paradigma da mobilidade (Creswell, 2006; Sheller e Urry, 2006) e assim legitimam o seu distanciamento das questões relacionadas com a migração. Nesta perspectiva, os sujeitos da mobilidade científica e académica não são imigrantes são, pois, cientistas internacionais, expatriados/as, professores/as e investigadores/ /as internacionais a quem não cabem vivências de imigrantes. Cria-se, portanto, uma categoria especial para referir a mão-de-obra qualificada que tem direito de circular, quase que livremente, pelas fronteiras dos Estados. Assim, ao diferenciar os/as investigadores/as, académicos/as e cientistas dos demais trabalhadores/as imigrantes (indesejados/ as) é possível oferecer aos primeiros uma série de privilégios e regalias (vistos, contratos de trabalho, acesso a saúde, programas de reunificação familiar) a que os membros do segundo grupo não têm acesso. Ou seja, a existência de duas categorias distintas para sujeitos em situações semelhantes permite a aplicação de políticas igualmente distintas. Neste sentido, enquanto a mobilidade científica é regida por políticas e programas de atracção e incentivo, a imigração é controlada por severas políticas restritivas e de criminalização. Assim, enquanto, os/as participantes dos programas de mobilidade serão bem-vindos/as por contribuírem para o desenvolvimento e crescimento económico da nação, os/ /as imigrantes serão cada vez mais perseguidos/as e estigmatizados/as como um grupo problemático, difícil de integrar e oneroso para os cofres públicos. Identifica-se, portanto, uma vez mais estratégias de diferenciação e inferiorização que atravessam o fenómeno da mobilidade científica com base numa ideologia estigmatizante e segregacionista.

Diante do exposto, percebe-se a complexidade da mobilidade científica académica como fenómeno social e a necessidade urgente de estudos que ultrapassem a leitura dessas deslocações como uma mera etapa inevitável da carreira académica. É fundamental discutir os pontos críticos da mobilidade académica e científica para que não se naturalize como mais uma dinâmica de segregação e exclusão social.

\section{Beatriz Padilla e Thais França}

\section{Referências bibliográficas}

CRESWELL, Tim (2006), On the move: Mobility in the modern Western World, New York, Routledge.

QUIJANO, Anibal (2009), "Colonialidade do poder e classificação social", in Santos, Boaventura de Sousa; Menezes, Maria Paula (Orgs), Epistemologias do Sul, Coimbra, Edições Almedina S.A., pp. 73-118.

SAID, Edward (1979), Orientalism, New York, Vintage.

SHELLER, Mimi e Urry, John (2006), "The New Mobility paradigm", Environment And Planning, A 38, pp. 207-226.

Recebido a 05/10/2015. Aceite para publicação a 05/12/2015.

Beatriz Padilla (padilla.beatriz@gmail.com). Instituto Universitário de Lisboa (ISCTE-IUL), Centro de Investigação e Estudos de Sociologia (CIES-IUL) \& Universidade Nova de Lisboa, Centro Interdisciplinar de Ciências Sociais (CICS.NOVA). CIES-IUL, Ed. ISCTE, Avenida das Forças Armadas, 1649-026 Lisboa, Portugal.

Thais França (thaisfrancas@gmail.com). Universidade do Minho, Centro Interdisciplinar de Ciências Sociais, CICS. NOVA (Polo UMinho). Campus de Gualtar, 4710-057 Braga, Portugal. 